\title{
Characteristics of Articles Published in Different Quartiles: A Bibliometric Analysis of Sport and Exercise Psychology Journals
}

\author{
Hakan Taş, Alena Mikhaylova, Hasan Ödemiş, Eylül Çisem Uçar, Mustafa Söğüt \\ Department of Physical Education and Sports, Middle East Technical University, \\ Faculty of Education, Ankara, Turkey
}

\begin{abstract}
Background. The purposes of this study were to determine the quantitative characteristics of the articles published in sports and exercise psychology journals in four quartiles of Web of Science and to understand whether these characteristics had any effect on citation.

Methods. Sport and exercise psychology journals indexed under the Sport Sciences subject category were included in the study. A total of 172 articles published in 2017, which was the most recent date meeting inclusion criteria, were collected from four sport and exercise psychology journals included: Psychology of Sport and Exercise (Q1), Journal of Sport and Exercise Psychology (Q2), Sport Psychologist (Q3), and International Journal of Sport Psychology (Q4).

Results. The articles published in Q1 journal were multi-institutional and multinational. Besides, they had longer abstracts and discussions and cited more references. The results revealed that multinational articles and articles with structured abstracts had higher citations than single country articles and articles with unstructured abstracts. The number of affiliated countries and references, and longer titles, abstracts, and introductions were found significantly associated with the number of citations. The bibliometric analysis indicated that the UK, the USA, and Canada were the major contributing countries.

Conclusion. This study is the first attempt to investigate the characteristics of articles published in different WoS quartiles within the field of sports and exercise psychology. The findings of the study may help researchers to improve their citation count.
\end{abstract}

Keywords: scientific productivity, essential science indicators, journal impact factor, Web of Science, scientometrics.

\section{INTRODUCTION}

$\mathrm{B}$ ibliometrics is defined as a discipline that includes both quantitative aspects of research and the exchange of scientific knowledge, along with processing, distribution, and reconstruction processes (Glänzel and Schoepflin, 1994). It provides a guideline to researchers by offering a comprehensive evaluation of the field of study, and attempts to highlight the publication template (Guilera, 2012). The ultimate focus of bibliometrics is to enhance scientific studies with the benefit of quantitative analysis of academic publications, such as documents and information, with the help of cooperation among researchers (Osareh, 1996). Measuring the effects of scientific articles and academic publications, evaluating scientific citations, and implementing these measures in the scope of strategy and organization have been established as significant research questions (Andrade, López, 
Beltrán, Ramirez-Campillo and Rodríguez, 2013). Bibliometric analysis can enlighten the effectiveness and efficiency of research distribution, which can be quantified, for example, according to the number of published research in a year across various fields (Baskurt, 2011). There are several rough estimates, by region, country, or institution, about how to evaluate scientific productivity, and the most frequently used methodology is bibliometric analysis since it provides systematic tendencies verification and shows prognoses (Baskurt, 2011). In general, journals, citation indexes, and impact factors are important resources for multi-level assessment, including country, organization, and discipline (Cartes-Velásquez and Aravena-Torres, 2012). Nevertheless, scientific productivity is defined as the article's publication statistics and generally consists of articles that only appear in indexed journals (Cartes-Velazquez and Aravena-Torres, 2012).

The Clarivate Analytics Web of Science (WoS) database is an online resource for academic information that includes most of the scientific fields which are globally explored (Falagas, Pitsouni, Malietzis and Pappas, 2008). It can effectively and quickly discover useful scientific research data by utilizing an effective search function, including a number of publications and citations, article sources, countries, and other indicators (Falagas et al., 2008). In 2014, there were about 2,810,016 active Englishlanguage peer-reviewed academic journals that had around 2.5 million publications per year globally (Plume and Van Weijen, 2014). More generally, over 90 million papers were included in the WoS database (Ware and Mabe, 2015). For such a wide range of publications, many indexing and conceptual resources use citation as an essential statistical measure to predict article quality, significance, and research impact (Hafeez, Jalal and Khosa, 2019). Even though the citation rate cannot be the only measure of a scientific study, it is considered a significant indicator of its value in the scientific community (Shadgan, 2010). Without a doubt, bibliometrics-based analysis in the science world has now gained significant attention (Agarwal et al., 2016). In comparison to the significance of scientific data, research findings in different disciplines have shown that there are many other factors that influence the citation rate of publications (Shekhani, Shariff, Bhulani, Khosa and Hanna, 2017; Khan et al., 2017). These factors include aspects that are linked to researchers, articles, and the journal itself (Hafeez et al., 2019). In addition, because of the number of citations depending on the field of citation processes, the characteristics that influence them often vary across each field (Moed, Burger, Frankfort and Van Raan, 1985).

There are several indicators to evaluate whether an article is cited, including the rate of publication, approval, and other quantities, such as the collaboration of researchers (LaBonte, 2005). Moreover, the scientific community receives the support of bibliometric data, including citation counts of articles, impact factors of journals for the collection of desired articles for research journals, and scientific exchanges within the academic disciplines (Sahu, Goswami and Chaudhury, 2011). Previous research on the characteristics of the frequently cited papers has shown that international cooperation among authors is a typical feature of the most cited papers (Fu, Chuang, Wang and Ho 2011; Miyairi and Chang, 2012; Pislyakov and Shukshina, 2014). Additionally, various scientists across different fields did research in order to determine the characteristics of highly cited papers in the WoS (Ho, 2014). Essential Science Indicators is a tool that identifies and ranks the research in WoS Core Collection, and it surveys thousands of journals around the world and then ranks authors, institutions, and journals in various fields based on their citation performance ( $\mathrm{Fu}$ et al., 2011). Moreover, Essential Science Indicators is commonly used in the bibliometric analysis in various fields such as articles published in the field of chemical engineering (Ho, 2012), pain-based research (Chuang and Ho, 2014), materials science (Ho, 2014), thermodynamic (Fu and Ho, 2015), biomass research (Chen and Ho, 2015).

Current literature provides limited evidence on the bibliometric analysis of articles on the field of sports and exercise psychology. Therefore, the purposes of this study were (i) to determine the quantitative characteristics of the articles published in sports and exercise psychology journals in four quartiles of Web of Science and (ii) to understand whether these characteristics had any effect on the number of the obtained citations.

\section{METHOD}

The WoS database was used as a source of bibliometric data, as well as a definitive guide for determining in what year all journals in all quartiles were identified. The journals indexed under the "Sport Sciences" subject category and in the field of sport and exercise psychology were included in the study. The search revealed that the journals 
indexed in all quartiles in the same calendar year were available in 2017, the most recent year meeting all inclusion criteria. There were two journals ranked into the second quartile, and only the one with a higher impact factor was included in the study. Consequently, the selected sports psychology and exercise journals were: Psychology of Sport and Exercise (Q1), Journal of Sport and Exercise Psychology (Q2), The Sport Psychologist (Q3), and International Journal of Sport Psychology (Q4). A total of 172 original articles (Q1: 88, Q2: 32, Q3: 28, Q4: 24) published in 2017 were collected. Sources such as abstracts, reviews, book chapters, editorials were excluded from this study. Two authors independently performed the selection of publications. The total number of citations for each journal was recorded at the end of 2020.

\section{Statistical analysis}

The descriptive statistics (mean and standard deviations) were calculated for study variables. SPSS 26.0 for Windows was used to conduct data analysis. The normality of the variables was initially checked in the inferential statistics, and then the histogram for the normality assumptions was evaluated. Since the data were not normally distributed, non-parametric tests were employed. The Kruskal-Wallis H test was used to determine the differences between quartiles. Tamhane's T2 regression for the post hoc analysis was conducted in the case to identify if there was a significant difference. The Spearman rank-order correlation was computed to analyze the associations between study variables and citations. The MannWhitney U test was carried out for the comparison of categorical variables. The alpha level was set to 0.05 .

\section{RESULTS}

\section{Descriptive statistics}

Based on the descriptive results (detailed information is presented in Table 1), the Q1 journal has more citations $(M=10.36, S D=7.60)$ than the other journals, and the Q4 journal has the least number of citations $(M=2.75, S D=2.87)$. The

Table 1. Descriptive statistics of the articles of the selected journals in different quartiles

\begin{tabular}{|c|c|c|c|c|c|}
\hline Quartiles & $\begin{array}{c}\mathrm{Q1} \\
(\mathrm{n}=88)\end{array}$ & $\begin{array}{c}\mathrm{Q2} \\
(\mathrm{n}=32)\end{array}$ & $\begin{array}{c}\text { Q3 } \\
(n=28)\end{array}$ & $\begin{array}{c}\mathrm{Q4} \\
(\mathrm{n}=24)\end{array}$ & $\begin{array}{c}\text { Total } \\
(\mathrm{n}=172)\end{array}$ \\
\hline Number of citations & $10.36(7.60)$ & $8.1(6.61)$ & $5.35(4.09)$ & $2.75(2.87)$ & $8.06(7.0)$ \\
\hline Number of words in title & $14.7(4.3)$ & $13.9(3.5)$ & $13.6(4.3)$ & $12.2(3.8)$ & $14.0(4.1)$ \\
\hline Number of characters in title & $110.4(31.0)$ & $105.4(25.5)$ & $98.9(26.6)$ & $93.8(29.1)$ & $105.3(29.5)$ \\
\hline Number of authors & $4.0(1.4)$ & $3.5(1.3)$ & $3.3(1.2)$ & $3.8(1.2)$ & $3.8(1.3)$ \\
\hline Number of institutions & $2.8(1.5)$ & $1.8(1.0)$ & $1.9(0.9)$ & $2.6(1.4)$ & $2.4(1.4)$ \\
\hline Number of countries & $1.6(0.9)$ & $1.2(0.4)$ & $1.2(0.4)$ & $1.5(0.7)$ & $1.5(0.8)$ \\
\hline Number of words in abstract & $222.4(33.1)$ & $149.3(19.4)$ & $134.2(18.2)$ & $150.5(43.1)$ & $184.4(49.7)$ \\
\hline Number of characters in abstract & $1568.9(232.4)$ & $1086.8(128)$ & $947.8(203.1)$ & $1039.7(280.1)$ & $1304.2(350.7)$ \\
\hline Number of keywords & $4.7(0.94)$ & $4.7(1.2)$ & $4.3(0.7)$ & $4.5(1.5)$ & $4.6(1.0)$ \\
\hline Number of words in introduction & $1515.1(604.4)$ & $1701.9(656.2)$ & $1330.6(427.1)$ & $1812.6(219.4)$ & $1561.3(981.1)$ \\
\hline Number of paragraphs in introduction & $8.8(3.5)$ & $9.9(4.0)$ & $7.6(2.0)$ & $8.9(4.1)$ & $8.8(3.6)$ \\
\hline $\begin{array}{l}\text { Number of words per paragraph in } \\
\text { introduction }\end{array}$ & $177.3(41.0)$ & $176.3(40.1)$ & $177.3(37.2)$ & $164.8(34.6)$ & $175.4(39.3)$ \\
\hline Number of figures & $1.1(1.3)$ & $1.9(1.4)$ & $0.8(1.0)$ & $1.2(1.1)$ & $1.2(1.3)$ \\
\hline Number of tables & $2.0(1.5)$ & $2.1(1.4)$ & $1.4(1.1)$ & $2.6(1.9)$ & $2.0(1.5)$ \\
\hline Number of words in discussion & $1830.7(619.8)$ & $1939.6(600.6)$ & $2003.8(665.6)$ & $1423.7(686.4)$ & $1822.3(651.5)$ \\
\hline Number of paragraphs in discussion & $10.6(3.7)$ & $11.6(3.6)$ & $10.8(3.6)$ & $8.6(3.8)$ & $10.5(3.7)$ \\
\hline $\begin{array}{l}\text { Number of words per paragraph in } \\
\text { discussion }\end{array}$ & $179.8(48.8)$ & $170.3(35.5)$ & $188.1(40.9)$ & $166.0(45.0)$ & $177.4(45.0)$ \\
\hline Number of references & $54.0(18.2)$ & $54.2(15.4)$ & $46.4(13.0)$ & $40.3(13.7)$ & $50.9(17)$ \\
\hline Number of pages & $9.0(1.8)$ & $12.3(2.3)$ & $12.1(2.3)$ & $9.2(2.3)$ & $10.1(2.53)$ \\
\hline
\end{tabular}


Figure 1. Top 25 contributing countries (at least one author was affiliated to a certain country)

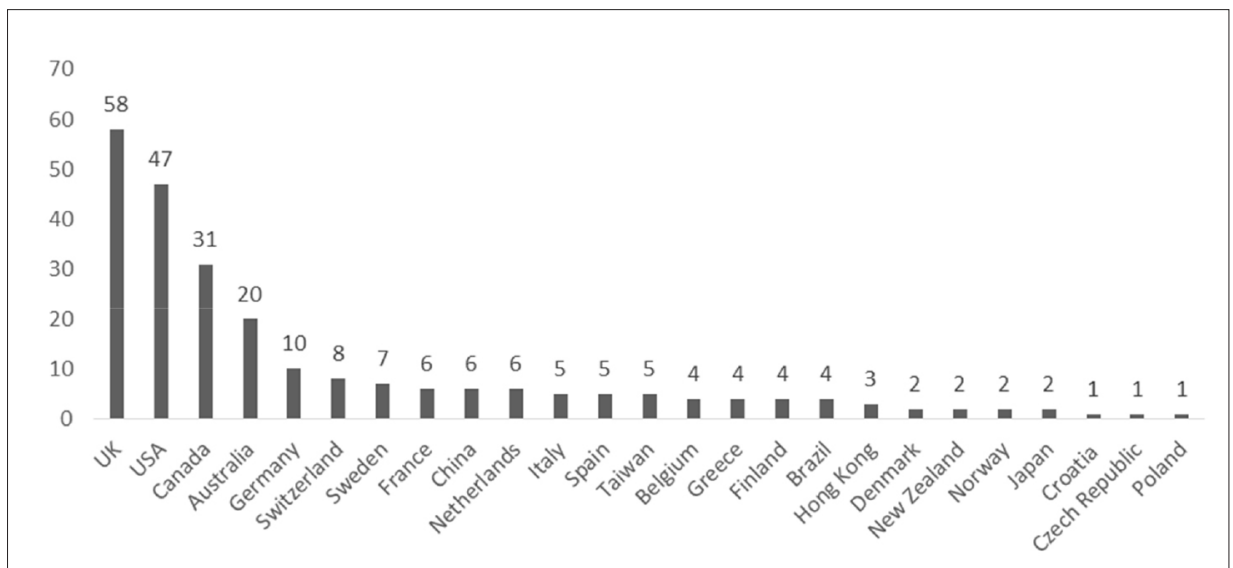

Figure 2. Top 25 contributing countries (the number of first authors affiliated to a certain country in the articles)

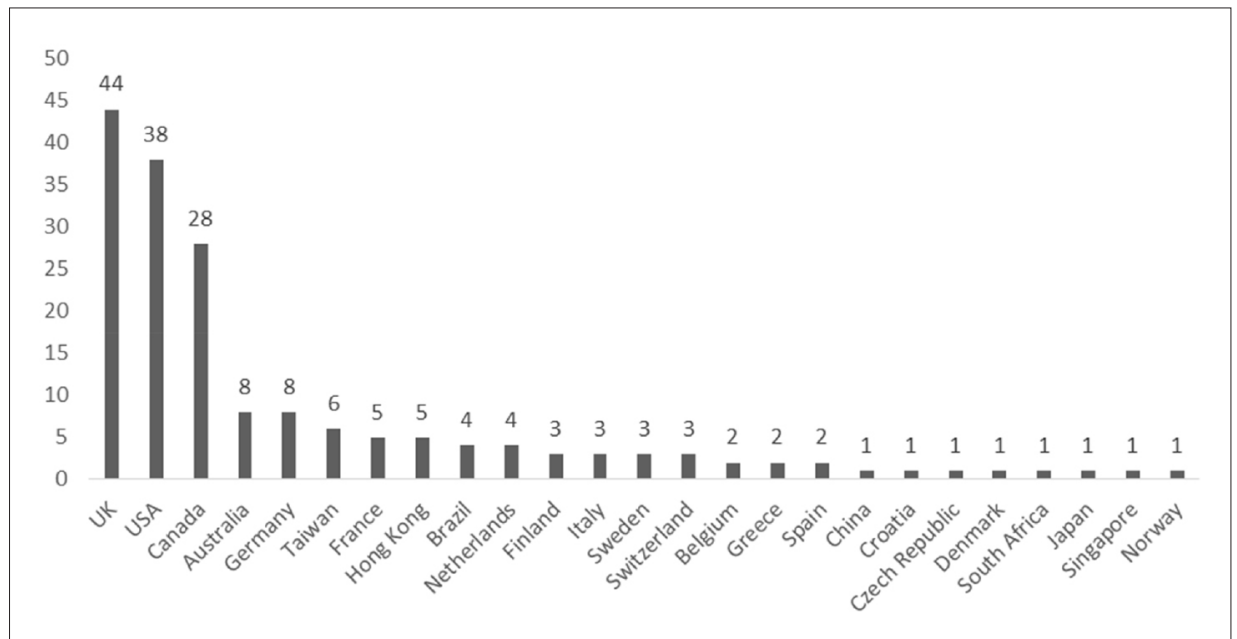

number of characters in the title is higher in Q1 than the other quartiles. There is approximately a 13-character-difference between Q1 and Q4. Especially, the number of words in the abstract is highest in Q1 $(M=222.4, S D=33.1)$. In addition to that, the number of characters in abstracts shows the same result $(M=1568.9, S D=232.4)$. In Q2, more figures are used $(M=1.9, S D=1.4)$ than the other quartiles. The number of words in introduction $(M=1812.6, S D=219.4)$, the number of words per paragraph in introduction $(\mathrm{M}=195.1, \mathrm{SD}=142.2)$, and the number of tables $(\mathrm{M}=2.6, \mathrm{SD}=1.9)$ were highest in the Q4 journals. However, the number of words in title, authors, institutions, countries, keywords, tables, word per paragraph in discussion and pages are similar or slightly different among the articles in different quartiles.

Figure 1 shows the top 25 countries where at least one author was affiliated in the articles. The results revealed that the UK (58), the USA (47), and Canada (31) were the most contributing countries, respectively. Figure 2 indicates the top 25 countries according to the number of first authors affiliated to a certain country in the articles. Based on the results, the UK (44), the USA (38), and Canada (28) were in the first three places, respectively.

Table 2 shows the most productive institutions in the articles. University of Alberta (Canada), Loughborough University (the UK), and University of Birmingham (the UK) published more articles than other institutes. In addition, there are 17 institutions from the UK, the USA, and Canada in the top 25 institutions.

\section{Inferential statistics}

Differences between four quartiles according to selected journals are presented in Table 3. The Kruskal-Wallis analysis revealed that Q1 articles had significantly higher citations than Q3 and Q4 articles. Besides, Q2 articles had more citations than Q4 articles. The results also indicated that Q1 articles had more institutions than Q2 and Q3 articles. Q1 articles were more multinational than Q2 and Q3 articles. Q1 articles had significantly more words in the abstract than the other quartiles. Also, Q2 articles had more words in abstract than Q3 articles. Q1 articles had more words in abstract than the other quartiles. Also, Q2 articles had more 
Table 2. The 25 most productive institutions according to selected journals
Table 3. Differences between four quartiles according to selected journals

\begin{tabular}{|c|c|c|c|}
\hline No & Institution & Country & Number of articles \\
\hline 1 & University of Alberta & Canada & 8 \\
\hline 2 & Loughborough University & UK & 7 \\
\hline 3 & University of Birmingham & UK & 7 \\
\hline 4 & Michigan State University & USA & 6 \\
\hline 5 & Sheffield Hallam University & UK & 6 \\
\hline 6 & University of Stirling & UK & 6 \\
\hline 7 & VU University Amsterdam & Netherlands & 6 \\
\hline 8 & Leeds Beckett University & UK & 5 \\
\hline 9 & University of Hong Kong & Hong Kong & 5 \\
\hline 10 & The Penn State University & USA & 5 \\
\hline 11 & Bangor University & UK & 4 \\
\hline 12 & Curtin University & Australia & 4 \\
\hline 13 & The Education University of Hong Kong & Hong Kong & 4 \\
\hline 14 & University of British Columbia & Canada & 4 \\
\hline 15 & University of Essex & UK & 4 \\
\hline 16 & University of Genève & Switzerland & 4 \\
\hline 17 & University of Jyvaskyla & Finland & 4 \\
\hline 18 & University of Ottawa & Canada & 4 \\
\hline 19 & University of Portsmouth & UK & 4 \\
\hline 20 & Cardiff Metropolitan University & UK & 3 \\
\hline 21 & Columbia University & USA & 3 \\
\hline 22 & National Taiwan Sport University & Taiwan & 3 \\
\hline 23 & Queen's University & Canada & 3 \\
\hline 24 & University of Bern & Switzerland & 3 \\
\hline 25 & University of Central Lancashire & UK & 3 \\
\hline
\end{tabular}

\begin{tabular}{|c|c|c|c|}
\hline Variables & $X^{2}$ & $L p$ & Post-hoc \\
\hline Number of citations & 38.994 & $<0.001$ & $\mathrm{Q} 1>\mathrm{Q} 3, \mathrm{Q} 4 ; \mathrm{Q} 2>\mathrm{Q} 4$ \\
\hline Number of words in title & 6.037 & 0.110 & - \\
\hline Number of characters in title & 6.185 & 0.103 & - \\
\hline Number of authors & 6.822 & 0.078 & - \\
\hline Number of institutions & 15.380 & 0.002 & $\mathrm{Q} 1>\mathrm{Q} 2, \mathrm{Q} 3$ \\
\hline Number of countries & 12.312 & 0.006 & Q1 > Q2, Q3 \\
\hline Number of words in abstract & 107.010 & $<0.001$ & $\mathrm{Q} 1>\mathrm{Q} 2, \mathrm{Q} 3, \mathrm{Q} 4 ; \mathrm{Q} 2>\mathrm{Q} 3$ \\
\hline Number of characters in abstract & 103.151 & $<0.001$ & $\mathrm{Q} 1>\mathrm{Q} 2, \mathrm{Q} 3, \mathrm{Q} 4 ; \mathrm{Q} 2>\mathrm{Q} 3$ \\
\hline Number of keywords & 5.726 & 0.126 & - \\
\hline Number of words in introduction & 5.622 & 0.132 & - \\
\hline Number of paragraphs in introduction & 6.207 & 0.102 & - \\
\hline Number of words per paragraph in introduction & 1.546 & 0.672 & - \\
\hline Number of figures & 12.373 & 0.006 & $\mathrm{Q} 2>\mathrm{Q} 3$ \\
\hline Number of tables & 7.167 & 0.067 & - \\
\hline Number of words in discussion & 11.675 & 0.009 & $\mathrm{Q} 2>\mathrm{Q} 4 ; \mathrm{Q} 3>\mathrm{Q} 4$ \\
\hline Number of paragraphs in discussion & 10.879 & 0.012 & $\mathrm{Q} 2>\mathrm{Q} 4$ \\
\hline Number of words per paragraph in discussion & 5.480 & 0.140 & - \\
\hline Number of references & 17.091 & 0.001 & $\mathrm{Q} 1>\mathrm{Q} 4 ; \mathrm{Q} 2>\mathrm{Q} 4$ \\
\hline Number of pages & 61.140 & $<0.001$ & $\mathrm{Q} 2, \mathrm{Q} 3>\mathrm{Q} 1, \mathrm{Q} 4$ \\
\hline
\end{tabular}


Table 4. Categorical variables and their citations according to selected journals

\begin{tabular}{|c|c|c|c|c|c|c|}
\hline \multirow{2}{*}{ Variables } & \multicolumn{2}{|c|}{ Yes } & \multicolumn{2}{|c|}{ No } & \multirow{2}{*}{$\boldsymbol{U}$} & \multirow{2}{*}{$p$} \\
\hline & n (\%) & citations & n (\%) & citations & & \\
\hline Study design stated in the title & $29(16.9 \%)$ & $6.59(5.36)$ & $143(83.1 \%)$ & $8.36(7.26)$ & 1776.00 & 0.223 \\
\hline Study findings stated in the title & $19(11.0 \%)$ & $8.95(5.84)$ & $153(89.0 \%)$ & $7.95(7.13)$ & 1225.00 & 0.263 \\
\hline Punctuations in the title & $137(79.7 \%)$ & $8.17(7.13)$ & $35(20.3)$ & $7.65(6.50)$ & 2283.00 & 0.663 \\
\hline Multi-institutional study & $119(69.2 \%)$ & $8.48(7.41)$ & $53(30.8 \%)$ & $7.13(5.90)$ & 2870.00 & 0.347 \\
\hline Multi-national study & $56(32.6 \%)$ & $9.79(6.51)$ & $116(67.4 \%)$ & $7.23(7.08)$ & 2412.00 & 0.006 \\
\hline Structured abstract & $82(47.7 \%)$ & $10.52(7.73)$ & $90(52.3 \%)$ & $5.82(5.37)$ & 2094.00 & $<0.001$ \\
\hline Open access & $33(19.2 \%)$ & $8.79(7.08)$ & $139(80.8 \%)$ & $7.89(6.98)$ & 2105.00 & 0.463 \\
\hline Funding & $64(37.2 \%)$ & $8.87(6.40)$ & $108(62.8 \%)$ & $7.58(7.30)$ & 2946.00 & 0.105 \\
\hline
\end{tabular}

Table 5. Correlations between study variables and number of citations

\begin{tabular}{|l|c|c|}
\hline \multicolumn{1}{|c|}{ Study Variables } & $\boldsymbol{r}$ & $\boldsymbol{p}$ \\
\hline Number of words in title & 0.256 & 0.001 \\
\hline Number of characters in title & 0.258 & 0.001 \\
\hline Number of authors & 0.060 & 0.198 \\
\hline Number of institutions & 0.099 & 0.003 \\
\hline Number of countries & 0.229 & $<0.001$ \\
\hline Number of words in abstract & 0.361 & $<0.001$ \\
\hline Number of characters in abstract & 0.371 & 0.069 \\
\hline Number of keywords & 0.139 & 0.009 \\
\hline Number of words in introduction & 0.200 & 0.037 \\
\hline Number of paragraphs in introduction & 0.160 & 0.987 \\
\hline Number of words per paragraph in introduction & 0.001 & 0.793 \\
\hline Number of figures & 0.020 & 0.177 \\
\hline Number of tables & -0.103 & 0.189 \\
\hline Number of words in discussion & 0.101 & 0.072 \\
\hline Number of paragraphs in discussion & 0.137 & 0.915 \\
\hline Number of words per paragraph in discussion & 0.008 & 0.031 \\
\hline Number of references & -0.034 & 0.60 \\
\hline Number of pages & & 0.164 \\
\hline
\end{tabular}

words in abstract than Q3 articles. Q2 and Q3 articles had more words in the discussion than Q4 articles. Q2 articles had more tables than Q3 articles. In Q1 and Q2 articles, more references were used than in Q4 articles. In Q2 and Q3 articles, more pages were used than Q1 and Q4 articles.

The Mann Whitney $U$ analyses between categorical variables were given in Table 4 . The results indicated that multinational articles and articles with structured abstracts had higher citations than single country articles and articles with unstructured abstracts.

The correlational analysis between study variables and the number of obtained citations are presented in Table 5. The results demonstrated that the number of affiliated countries and references and longer titles, abstracts, and introductions were significantly and positively associated with the number of citations.

\section{DISCUSSION}

This study is the first attempt to identify characteristics of articles in sports and exercise psychology journals in different quartiles and their influences on the number of citations. The main findings indicated that the articles published in the Q1 journal were characterized by higher number of citations and longer and structured abstracts. Additionally, they were more multi-institutional and multinational. Moreover, the findings of the study showed that the UK, the USA, and Canada 
were the major countries contributing most to the sport and exercise psychology field while the most productive institutes were from Canada (Alberta University) and the UK (Loughborough University and Birmingham University).

According to the findings, there were statistically significant differences in abstract length among the quartiles. The articles in the Q1 journal had more words and characters in abstract than did the articles in other quartiles. The abstract might be an important factor in the representation of the articles since it is the first to be read. In addition, the abstract includes the key points and summarizes the main findings of the article by highlighting the importance of the study. However, in contrast to the findings of this study, Letchford, Preis and Moat (2016) found that journals publishing papers with shorter abstracts receive slightly more citations. Furthermore, in the comparison variables with citation, the findings of the study showed that there was a statistically significant difference between articles having structured abstracts and articles having non-structured abstracts. Khasseh and Biranvand (2013) found that by using structured abstracts, authors could reflect the study results to other researchers better and increase the citation capability since structured abstracts are more effective in presenting organized information of the study. The Q1 journal published articles with structured abstracts; however, other quartiles' journals published articles with non-structured abstracts. This might be why there was a statistical difference between the articles with structured abstracts and unstructured abstracts.

In terms of the number of institutions and countries, the findings revealed statistically significant differences among the quartiles. The articles in Q1 were more multinational and multiinstitutional than those in Q2 and Q3. However, there was no difference between the articles in Q1 and Q4. The findings of the study revealed that there was a positive relationship between citation and multinational studies. Previous research findings indicated that multinational studies are more cited than non-multinational studies (de Moya-Anegon, Guerrero-Bote, Lopez-Illescas and Moed, 2018; van Raan, 1998; Katz and Hicks, 1997; Narin, 1991). The reason might be that multinational studies imply international collaboration and thus have more representatives and reach more researchers than non-multinational studies (van Raan, 1998). Another reason might be that multinational studies may have more opportunities to conduct the research in different countries and reach more participants (van Raan, 1998); therefore, the findings of the study could present more precise data, leading to more citations. Furthermore, when analyzing the effect of multi-institution on citation, the findings of the study found no correlation between the number of citations and the number of institutions. Supportively, Okike and colleagues (2011) found that multi-institutional studies are more cited than single-institution studies.

Based on the findings, the most productive countries in the sports and exercise psychology field were the UK, the USA, and Canada, respectively. In a recent study, Tomanek and Lis (2020) examined the scientific production of research in physical education. Their results indicated similarities as the UK and the USA were found the most productive countries. In addition, in their highly cited article in the Education and Educational Research study, Ivanovic and Ho (2019) found that the UK, the USA, and Canada were the top three contributors to the relevant field. In their physical activity and aging study, Müller and colleagues (2015) similarly found that the UK, the USA, and Canada were top contributors to the related area. The reason why the UK, the USA, and Canada are so influential in the mentioned fields, as well as sports and exercise psychology, might be due to more available funding opportunities and higher number of well-trained scientists, especially in these countries (Müller, Ansari, Ale Ebrahim and Khoo, 2015).

The results regarding the correlation analysis showed a positive correlation between citation and the number of words and characters in the title. The reason may be that longer and more comprehensive titles could include more keywords, increasing discoverability and visibility in databases (Jacques and Sebire 2010). In contrast to the finding of this study, Jamali and Nikzad's study (2011) showed a negative correlation between title length and citations. The results also demonstrated a positive correlation between the number of countries and citation. The articles published in Q1 journal had more citations and were more multinational and multi-institutional than those in Q2 and Q3. Similarly, previous studies reported that multinational and multi-institutional studies had more citations than studies with single institutions (Narin, 1991), and adding an author from a foreign institution to a study gives better results than adding an author from a domestic institution in 
terms of citation (Katz and Hicks, 1997). However, Antoniou et al. (2015) found no correlation between citation and the number of countries. The results showed a positive relationship between citation and the number of words and characters in the abstract. Weinberger et al. (2015) found that shorter abstracts led to fewer citations. In contrast to the findings of this study, Letchford and colleagues (2016) suggested that journals publishing articles with shorter abstracts receive slightly more citations per paper. Furthermore, Falagas, Zarkali, Karageorgopoulos, Bardakas and Mavros (2013) found no correlation between citation and the number of words and characters in abstracts and concluded that abstract length was not an indication of citation. According to the study findings, there was a positive relationship between citation and the number of words in the introduction. Although there are no significant differences between journals included in this study, the number of words in the introduction section is associated with an increased citation rate. The reason may be that it is the most challenging section to write in a paper since this section makes the first impression, and a longer introduction section may imply in-depth knowledge of the related field (Suryani et al., 2015). Based on the findings of the study, there was a positive relationship between the number of references and citations. Ahlgren, Colliander and Sjögårde (2018) found that the number of references correlates with the citation impact of the study. The reason why references have a positive relationship with citation may be that using several references may imply a good amount of knowledge of the research field (Onodera and Yoshikane, 2015; Ahlgren, Colliander and Sjögårde, 2018).
In conclusion, this study is original in the sense that it presents a bibliometric analysis of sport and exercise psychology articles published in journals of different WoS quartiles. Furthermore, it is the first attempt to identify quantitative characteristics of articles and their influences on the number of citations. The articles published in Q1 journal were characterized by higher citations and were multiinstitutional and multinational. They also had longer abstracts and discussions and cited more references. Multinational articles and articles with structured abstracts had higher citations than single country articles and articles with unstructured abstracts. The number of affiliated countries and references, and the longer titles, abstracts, and introductions were significantly and positively associated with the number of citations. The results might be a guide for researchers interested in publishing scientific articles in the field of sport and exercise psychology. This study had several limitations. Firstly, only the WoS database was used as a source. Second, the obtained citations were extracted from approximately a three-year time frame. Thirdly, only four journals in different quartiles were selected and analyzed. Thus, it is warranted for future researches to examine citations analysis in a larger time frame, involve other databases, and include more journals from different quartiles.

\section{Declaration of competing interest}

The authors declare that they have no known competing financial interest or personal relationship that could have appeared to influence the work reported in this paper.

\section{REFERENCES}

Agarwal, A., Durairajanayagam, D., Tatagari, S., Esteves, S. C., Harlev, A., Henkel, R., ... \& Bashiri, A. (2016). Bibliometrics: tracking research impact by selecting the appropriate metrics. Asian Journal of Andrology, 18(2), 296. doi: https://doi.org/10.4103/1008682X.171582

Ahlgren, P., Colliander, C., \& Sjögårde, P. (2018). Exploring the relation between referencing practices and citation impact: A large-scale study based on Web of Science data. Journal of the Association for Information Science and Technology, 69(5), 728-743. doi: https://doi. org/10.1002/asi.23986

Akinlolu, M., Haupt, T. C., Edwards, D. J., \& Simpeh, F. (2020). A bibliometric review of the status and emerging research trends in construction safety management technologies. International Journal of Construction Management, 1-13. doi: https://doi.org/10.1080/156235 $\underline{99.2020 .1819584}$

Andrade, D. C., López, B. A., Ramírez-Campillo, R., Beltrán, A. R., \& Rodríguez, R. P. (2013). Bibliometric analysis of South American research in sports science from 1970 to 2012. Motriz: Revista de Educação Física, 19(4), 783-791. doi: https://doi.org/10.1590/ $\underline{\text { S1980-65742013000400017 }}$

Antoniou, G. A., Antoniou, S. A., Georgakarakos, E. I., Sfyroeras, G. S., \& Georgiadis, G. S. (2015). Bibliometric analysis of factors predicting increased citations in the vascular and endovascular literature. Annals of Vascular 
Surgery, 29(2), 286-292. doi: https://doi.org/10.1016/j. avsg.2014.09.017

Baskurt, O. K. (2011). Time series analysis of publication counts of a university: what are the implications? Scientometrics, 86(3), 645-656. doi: https://doi. org/10.1007/s11192-010-0298-1

Cartes-Velásquez, R., \& Aravena-Torres, P. (2012). Bibliometric profile of Chilean dentistry, 20012010. Revista Clinica de Periodoncia, Implantología y Rehabilitación Oral, 5(1), 5-8. doi: https://doi. org/10.4067/S0719-01072012000100001

Chen, H., \& Ho, Y. S. (2015). Highly cited articles in biomass research: A bibliometric analysis. Renewable and Sustainable Energy Reviews, 49, 12-20. doi: https:// doi.org/10.1016/j.rser.2015.04.060

Chuang, K. Y., \& Ho, Y. S. (2014). A bibliometric analysis on top-cited articles in pain research. Pain Medicine, 15(5), 732-744. doi: https://doi.org/10.1111/ pme. 12308

De Moya-Anegon, F., Guerrero-Bote, V. P., LópezIllescas, C., \& Moed, H. F. (2018). Statistical relationships between corresponding authorship, international coauthorship, and citation impact of national research systems. Journal of Informetrics, 12(4), 1251-1262. doi: https://doi.org/10.1016/j.joi.2018.10.004

Falagas, M. E., Pitsouni, E. I., Malietzis, G. A., \& Pappas, G. (2008). Comparison of PubMed, Scopus, web of science, and Google scholar: strengths and weaknesses. The FASEB Journal, 22(2), 338-342. doi: https://doi.org/10.1096/fj.07-9492LSF

Falagas, M. E., Zarkali, A., Karageorgopoulos, D. E., Bardakas, V., \& Mavros, M. N. (2013). The impact of article length on the number of future citations: a bibliometric analysis of general medicine journals. PLoS One, 8(2), e49476. doi: https://doi.org/10.1371/journal. pone. 0049476

Fu, H. Z., Chuang, K. Y., Wang, M. H., \& Ho, Y. S. (2011). Characteristics of research in China assessed with Essential Science Indicators. Scientometrics, 88(3), 841862. doi: https://doi.org/10.1007/s11192-011-0416-8

$\mathrm{Fu}$, H. Z., \& Ho, Y. S. (2015). Top cited articles in thermodynamic research. Journal of Engineering Thermophysics, 24(1), 68-85. doi: https://doi.org/10.1134/ $\underline{\mathrm{S} 1810232815010075}$

Glänzel, W., \& Schoepflin, U. (1994). A stochastic model for the ageing analyses of scientific literature. Scientometrics, 30(1), 49-64. doi: https://doi. org/10.1007/BF02017212

Guilera, G., Barrios, M., \& Gómez-Benito, J. (2013). Metaanalysis in psychology: a bibliometric study. Scientometrics, 94(3), 943-954. doi: https://doi.org/10.1007/s11192-012$\underline{0761-2}$

Hafeez, D. M., Jalal, S., \& Khosa, F. (2019). Bibliometric analysis of manuscript characteristics that influence citations: A comparison of six major psychiatry journals. Journal of Psychiatric Research, 108, 90-94. doi: https://doi.org/10.1016/j.jpsychires.2018.07.010

Ho, Y. S. (2012). Top-cited articles in chemical engineering in Science Citation Index Expanded: A bibliometric analysis. Chinese Journal of Chemical Engineering, 20(3), 478-488. doi: https://doi. org/10.1016/S1004-9541(11)60209-7

Ho, Y. S. (2014). A bibliometric analysis of highly cited articles in materials science. Current Science, 15651572.

Ivanović, L., \& Ho, Y. S. (2019). Highly cited articles in the Education and Educational Research category in the Social Science Citation Index: a bibliometric analysis. Educational Review, 71(3), 277-286. doi: https://doi.org /10.1080/00131911.2017.1415297

Jacques, T. S., \& Sebire, N. J. (2010). The impact of article titles on citation hits: an analysis of general and specialist medical journals. JRSM Short Reports, 1(1), 1-5. doi: https://doi.org/10.1258/shorts.2009.100020

Jamali, H. R., \& Nikzad, M. (2011). Article title type and its relation with the number of downloads and citations. Scientometrics, 88(2), 653-661. doi: https:// doi.org/10.1007/s11192-011-0412-z

Katz, J., \& Hicks, D. (1997). How much is a collaboration worth? A calibrated bibliometric model. Scientometrics, 40(3), 541-554. doi: https://doi. org/10.1007/BF02459299

Khan, M. S., Usman, M. S., Fatima, K., Hashmani, N., Siddiqi, T. J., Riaz, H., ... \& Khosa, F. (2017). Characteristics of highly cited articles in interventional cardiology. The American Journal of Cardiology, 120(11), 2100-2109. doi: https://doi.org/10.1016/j. amjcard.2017.08.030

Khasseh, A. A., \& Biranvand, A. (2013). Structured vs. unstructured abstract: a different look at Iranian journals of library science. International Research Journal of Applied and Basic Sciences, 4(7), 1706-1709.

LaBonte, K. B. (2005). Citation Analysis: A Method for Collection Development for a Rapidly Developing Field. Issues in Science and Technology Librarianship. 43(2). doi: https://doi.org/10.5062/F4TX3CB1

Letchford, A., Preis, T., \& Moat, H. S. (2016). The advantage of simple paper abstracts. Journal of Informetrics, 10(1), 1-8.

Miyairi, N., \& Chang, H. W. (2012). Bibliometric characteristics of highly cited papers from Taiwan, 20002009. Scientometrics, 92(1), 197-205. doi: https://doi. org/10.1007/s11192-012-0722-9

Moed, H., Burger, W., Frankfort, J., \& Van Raan, A. (1985). The application of bibliometric indicators: important field-and time-dependent factors to be considered. Scientometrics, 8(3-4), 177-203. doi: https:// doi.org/10.1007/BF02016935

Müller, A. M., Ansari, P., Ebrahim, N. A., \& Khoo, S. (2016). Physical activity and aging research: a bibliometric analysis. Journal of Aging and Physical Activity, 24(3), 476-483. doi: https://doi.org/10.1123/ japa.2015-0188

Narin, F., Stevens, K., \& Whitlow, E. S. (1991). Scientific co-operation in Europe and the citation of multinationally authored papers. Scientometrics, 21(3), 313-323. doi: https://doi.org/10.1007/BF02093973 
Okike, K., Kocher, M. S., Torpey, J. L., Nwachukwu, B. U., Mehlman, C. T., \& Bhandari, M. (2011). Level of evidence and conflict of interest disclosure associated with higher citation rates in orthopedics. Journal of Clinical Epidemiology, 64(3), 331-338.

Onodera, N., \& Yoshikane, F. (2015). Factors affecting citation rates ofresearch articles.Journal of the Association for Information Science and Technology, 66(4), 739-764. doi: https://doi.org/10.1002/asi.23209

Osareh, F. (1996). Bibliometrics, citation analysis and co-citation analysis: A review of literature I. Libri, 46(3), 149-158. doi: https://doi.org/10.1515/libr.1996.46.4.217 Plume, A., \& Van Weijen, D. (2014). Publish or perish? The rise of the fractional author. Research Trends, 38(3), 16-18.

Pislyakov, V., \& Shukshina, E. (2014). Measuring excellence in Russia: Highly cited papers, leading institutions, patterns of national and international collaboration. Journal of the Association for Information Science and Technology, 65(11), 2321-2330. doi: https:// doi.org/10.1002/asi.23093

Raan,A.V.(1998).Theinfluenceofinternationalcollaboration on the impact of research results. Scientometrics, 42(3), 423-428. doi: https://doi.org/10.1007/BF02458380

Sahu, A. K., Goswami, N. G. and Choudhury, B. K.(2011), "Research publications of metallurgical laboratory during the year 2001-2010: a study on citation patterns", Annals of Library and Information Studies, Vol.58, June, pp.151-160.

Shadgan, B., Roig, M., HajGhanbari, B., \& Reid, W. D. (2010). Top-cited articles in rehabilitation. Archives of physical medicine and rehabilitation, 91(5), 806-815. doi: https://doi.org/10.1016/j.apmr.2010.01.011

Shekhani, H. N., Shariff, S., Bhulani, N., Khosa, F., \& Hanna, T. N. (2017). Bibliometric analysis of manuscript characteristics that influence citations: a comparison of six major radiology journals. American Journal of Roentgenology, 209(6), 1191-1196. doi: https://doi. org/10.2214/AJR.17.18077

Suryani, I., Aizan, Y., \& Aziz, N. H. A. (2015). Introduction Sections of Research Articles with High and Low Citation Indices. Pertanika Journal of Social Sciences \& Humanities, 23(4).

Tomanek, M., \& Lis, A. (2020). Managing information on the physical education research field: Bibliometric analysis. Physical Education of Students, 24(4), 213226. doi: https://doi.org/10.15561/20755279.2020.0404

Ware, M., \& Mabe, M. (2015). The STM report: An overview of scientific and scholarly journal publishing. Retrieved January 10, 2021, from https://digitalcommons. unl.edu/scholcom/9/ 